\title{
ASSESSMENT OF PREDICTORS OF EARLY MORTALITY IN PATIENTS STARTING CHRONIC HAEMODIALYSIS IN A TERTIARY CARE CENTER.
}

Shahid Abbas, Riaz Hussain

1. Professor. Department of General Medicine, Sri Aurobindo Institute of Medical Sciences \& PG Institute, Indore, Madhya Pradesh.

2. Professor. Department of General Medicine, Sri Aurobindo Institute of Medical Sciences \& PG Institute, Indore, Madhya Pradesh.

\section{CORRESPONDING AUTHOR:}

Dr. Shahid Abbas,

21, Babji Nagar,

Behind Sagar automobiles near Shalimar township,

A. B. Road, Near Dewas Naka. Indore (M.P.).

E-mail: drshahidabbas786@gmail.com

Ph: 00919993986152

ABSTRACT: BACKGROUND: Mortality risk among haemodialysis (HD) patients may be highest soon after initiation of HD. Studies from different geographical areas have been published regarding the predictors of early mortality among incident haemodialysis patients. With this background we started our study to asses early mortality causes among incident haemodialysis patients in our institute in Central India so that group of patients with risk factors can be educated and can be intervened early. MATERIALS \& METHODS: 215 patients eligible for the evaluation of mortality in the first 120 days of dialysis were reviewed for their clinical and biochemical data. Univariate statistical tests using chi-square for binary variables and t-test for continuous variables were performed. RESULTS: The overall incident mortality within 120 days was 39 (18.1\%) patients of which cardiovascular causes accounted for $51 \%$ of all the causes. Early mortality rate was not significantly increased in the comparison of gender groups but increased in patients with diabetes mellitus (29.4\% vs.14.6\%), those with reduced dialysis frequency ( $27.9 \%$ vs. $11.6 \%$ ), the presence of low serum albumin (34.2\% vs. $9.3 \%)$, the presence of a central venous catheter (26.7\% vs. $10.1 \%)$ and the lack of Pre-ESRD nephrology care $(23.6 \%$ vs. $11.6 \%)$ and in old age. The low serum albumin below $35 \mathrm{~g} / \mathrm{l}$ was the strongest predictor of early mortality, the survival rates in patients with serum albumin less than $35 \mathrm{~g} / \mathrm{l}$ and those with serum albumin equal to or greater than $35 \mathrm{~g} / \mathrm{l}$ were $65.8 \%$ and $90.7 \%$, respectively $(\mathrm{p}<0.001)$. CONCLUSION: The present study suggest that the important predictors of early mortality in the first 120 days of starting HD include the presence of diabetes mellitus, decreased frequency of dialysis sessions, the presence of low serum albumin, the presence of a central venous catheter, presence of urinary tract infection and the lack of PreESRD nephrology care. These results also support the importance of arterio-venous fistula placement in the predialysis period with avoidance of temporary or permanent catheter placement and adequate predialysis nephrology care with a nephrologist at least 1 month before HD.

KEY WORDS: Haemodialysis (HD), Predictors, Early mortality, Serum albumin, Cardiovascular, Referral. 
INTRODUCTION: Mortality rates among haemodialysis (HD) patients exceed $20 \%$ per year $^{(1)}$ and a higher mortality rate within the first year after initiation of HD has been described. ${ }^{(2)}$ Over the years selection criteria for acceptance on renal replacement therapy (RRT) became more liberal leading to an increase in the number of patients receiving this modality of treatment all over the world. This proportion was associated with increased proportion of elderly patients and those with co-morbidities.

Various studies showed early mortality occurring in first 120 days after starting RRT represented a high percentage of first year mortality rate $(27.5 \mathrm{vs} .21 .9$ deaths per 100 personyears; $P$ 0.002). ${ }^{(3)}$ Identifying the period of highest risk for death after initiation of HD and factors that are associated with this higher risk are important to the care of patients who are new to HD (incident). Observational studies among prevalent haemodialysis patients have identified patient characteristics that are associated with greater mortality risk, including older age, low serum albumin levels, low and elevated serum phosphorus levels, anaemia, and cardiovascular disease (traditional risk factors), ${ }^{(4-10)}$ as well as other non-traditional risk factors including C-reactive protein and IL-6 levels. (11-12) Hypoalbuminemia has been demonstrated by most studies to be an adverse prognostic indicator in long term survival on RRT. (7,12) Studies also have supported the importance of early nephrology referral in the predialysis period for reducing mortality after HD initiation as well as highlighting importance of the ongoing recommendations for arterio-venous fistula placement in the predialysis period and avoidance of temporary or permanent catheter placement.(3,13-14) Though the studies that have assessed mortality rates or risk predictors in the period immediately after HD initiation suggest an elevated mortality risk in the first 90 days, but it is unclear whether that elevation is limited to the first 90 days.

MATERIAL AND METHODS: A retrospective cohort study design was used to identify mortality risk factors. All patient information was collected at time of enrollment. We reviewed the records of 442 new patients started on renal replacement therapy at Sri Aurobindo Institute of Medical Sciences, Indore (M.P) between October 2009 and September 2012. We excluded patients with acute renal failure, rapidly progressive renal failure, acute on chronic renal failure, chronic renal failure with recovering residual renal function after a short period of RRT, patients with extrarenal diseases conferring poor prognosis independent of dialysis effect, such as neoplasia (primary or metastatic) and myeloma, and those with incomplete data especially serum albumin. There were 215 patients for the evaluation of mortality in the first 120 days of dialysis.

The reviewed clinical data included age, gender, body mass index (BMI), cause of renal disease, comorbidity, first mode of haemodialysis (emergency or programmed dialysis), dialysis frequency (two times or three times a week), mortality within the first 120 days, and causes and duration to mortality. The laboratory parameters were recorded at starting haemodialysis and included blood urea nitrogen (BUN), creatinine clearance (Clcr) using Cockroft-Gault formula, total serum cholesterol, triglycerides, potassium, calcium, phosphorus, uric acid, alkaline phosphatase, haemoglobin level, leucocytes count and urinalysis.

STATISTICAL ANALYSIS: In order to determine which parameters were associated with early mortality, patients who died within the first 120 days were compared to those who survived. Univariate statistical tests using chi-square for binary variables and t-test for continuous 
variables were performed. The statistical significance was set at $\mathrm{p} \leq 0.05$. Continuous variables are given as Mean \pm SD.

OBSERVATION: The Clinical and biochemical parameters of the study patients are summarized in Table 1 . The average age was $49.1 \pm 15.9$ years. Out of 215 available for evaluation, 39 (18.1\%) died in the first 120 days after starting chronic haemodialysis. Overall $38 \%$ of the patients were $65 \mathrm{yr}$ older and of the total $60 \%$ were male.

Age was not different between the deceased and survivors; the mean age was $48.9 \pm$ 17.4 and $47.4 \pm 17$ years, respectively. Furthermore, there was difference in the mortality between patients aged less than 65 and those aged 65 years or more $(15 \%$ and $31.5 \%$, respectively). There was also no significant difference of early mortality between males and females, $20.5 \%$ Vs $17.7 \%$, respectively. Other variables that were not associated with early mortality included: BMI, first dialysis (emergency or not), serum uric acid, serum phosphorus, serum calcium, cholesterol level, creatinine clearance, BUN, coma and ventilator dependency.

Cardiovascular causes accounted for the most deaths and accounted for $51 \%$ of the reported causes of mortality and included pulmonary edema, pericarditis, severe cardiac failure, myocardial infarction, cardiac arrhythmia, atherosclerotic heart disease and cerebrovascular accident (Table 2).

Table 3 shows several clinical and biological parameters that were associated with poor prognosis in the short term using the Univariate analysis. We found that patients with normal or low blood pressure had worse prognosis compared to those with chronic hypertension; rate of early mortality was $28.7 \%$ vs. $13.4 \%$, respectively, $(\mathrm{p}<0.05)$. The presence of diabetes mellitus or amyloidosis was associated with high rate of early mortality, $294 \%$ and $38.4 \%$, respectively. The patients with urinary tract infection had significantly higher early mortality rate than those without infection $29.8 \%$ vs. $14.9 \%$ respectively. The patients treated on haemodialysis two times a week had significantly higher mortality than those treated three times a week, $27.9 \%$ vs. $11.6 \%$, respectively. Hypoalbuminemia less than $35 \mathrm{~g} / 1$ was associated with poorer prognosis than the patients with serum albumin concentration of $35 \mathrm{~g} / 1$ or more, $34.2 \%$ vs. 9.3\%, respectively $(\mathrm{p}<0.001)$. Hypoalbuminemia had the strongest predictive value of early mortality Predialysis nephrology care was strongly associated with lower mortality $11.6 \%$ vs. $23.6 \%$ for those who don't received it during this period, highlighting the potential benefits of contact with a Nephrologist at least 1 month before HD. The e arly arterio-venous fistula placement in the predialysis period and avoidance of temporary or permanent catheter placement was related to lower mortality rates $10.1 \%$ vs. $26.7 \%$ catheter induced.

Other biochemical parameters that were significantly different between the deceased and surviving groups included elevated leukocyte count, triglycerides and decreased haemoglobin levels.

DISCUSSION: In this study we found an early mortality rate of $18.1 \%$ in our population of chronic dialysis. The estimated early mortality rate varied in the medical literature from $11 \%$ to $26 \%{ }^{(1,2,3,4)}$ This variation between centers is due to different methodologies used in the collection and analysis of data. There was influence of advanced age on early mortality in our study compared to other studies. Life expectancy is short for many elderly patients after dialysis initiation, but this varies widely and is based more on comorbidities than on numerical age.

Our study showed that early mortality was not statistically different between males and females. Some studies reported lower risk of mortality in females in a one-year survival analysis. ${ }^{(15)}$ 
Cardiovascular causes accounted for the largest percentage (51\%) of deaths during the first year, but the rate of cardiovascular-related deaths was considerably higher in the first 120 days. Patients who were older, with low serum albumin levels, diabetic, a catheter access in place at first dialysis, a history of congestive heart failure (CHF), or patients who did not visit a Nephrologist at least 1 month before initiating HD, had two times a week dialysis frequency were at significantly elevated risk for mortality within 120 days of initiating HD. A Michigan study of nearly 2400 patients with ESRD reported deaths within 90 days of initiation of dialysis in $10 \%$ of patients. ${ }^{(16)}$ Soucie and McClellan (17) reported $9 \%$ of HD patients in an ESRD registry in the south-eastern United States died within 90 days after dialysis initiation. Studies that were conducted in non-population-based samples of incident patients have reported 90-d mortality rates ranging from $12^{(18-20)}$ to $16 \%{ }^{(21)}$.

Early nephrological referral seemed to be beneficial in the short-term prognosis in patients starring RRT.(22,23)Early mortality was more frequent in the group of late referral.(13) There was statistical correlation between reduced early mortality (11.6 \% vs. $23.6 \%$ ) and regular nephrological follow- up which was in accordance with other studies. In our study, dysrhythmia, ischemic heart disease and cardiac failure was associated with poor prognosis.(24) Furthermore, we did not find coma and ventilator dependence associated with early mortality as in previous studies.

Though the cardiovascular comorbidity was the most common cause of death in our study and there were no withdrawals of patients from dialysis. Low haematocrit was associated with increased mortality in haemodialysis patients $(8,9)$

One of the major prognostic indicators in our study was the primary renal disease. Diabetes mellitus and amyloidosis were associated with the highest mortality rates. Diabetes mellitus is well known in long term survival studies to carry poor prognosis ${ }^{(9)}$

Mortality in amyloidosis, may be due to Addisonian crisis secondary to adrenocortical insufficiency related to amyloid deposits in the adrenal glands.(25) Detecting this disorder systematically at starting of chronic haemodialysis may be indicated. In this study, glomerulonephritis and polycystic kidney disease seemed to be associated with low risk of mortality, a finding that was noted in many other series. $(2,3)$

Chronic haemodialysis is associated with a typical atherogenic profile consisting mainly of hypertriglyceridemia with increased very low-density lipoprotein (VLDL) and low- density lipoprotein (LDL).(26) This explains why cardiovascular etiologies remained the most frequent cause of mortality in patients on RRT over the years. In our study, the Univariate analysis showed that hypertriglyceridemia was associated with excess of mortality. Low systolic blood pressure as a marker of severe cardiac failure has been reported as an adverse prognostic indicator in acute renal failure. This was also demonstrated in a prospective study in the chronic dialysis population.(20)

Up to $40.4 \%$ of our patients were dialyzed twice a week and this group had higher risk of early mortality than those dialyzed thrice a week , $27.9 \%$ vs. $11.6 \%$ respectively. The adverse effect of shorter treatment time and low delivered dialysis dose is well known to increase mortality.

One of the powerful independent predictors of mortality in patients on RRT is hypoalbuminemia, an indicator of malnutrition serum albumin was found to be a predictive factor of hospitalization and mortality(27-29). Hypoalbuminemia was suggested as a component of the acute- phase response. In our study, patients with low serum albumin had a high mortality rate. However, the low serum albumin did not correlate with the adequacy of dialysis estimated 
by the urea reduction rate. Furthermore, $C$ reactive protein and serum amyloid A, Interleukin 6 were suggested as determinants of serum albumin concentration in haemodialysis patients.(12.30) We conclude that our study findings suggest that the important predictors of early mortality in the first 120 days of start on haemodialysis include the presence of diabetes mellitus, the decreased frequency of dialysis sessions and the presence of hypoalbuminemia. The low serum albumin below $35 \mathrm{~g} / \mathrm{l}$ was the strongest predictor of early mortality. The importance of the ongoing recommendations for arterio-venous fistula placement in the predialysis period and avoidance of temporary or permanent catheter placement (31) to avoid catheter induced infections needs to be highlighted. Furthermore, these results suggest that greater medical attention, patient education and guidance before ESRD onset may lead to improved survival.(32)

CONCLUSION: This study suggests that a period of elevated mortality risk for patients who initiate HD extends to approximately 120 days after dialysis initiation. Excess early mortality was observed for all causes of death with cardiac causes showing the largest increase in early mortality. Thus the early mortality among patients with incident HD can be decreased by patients following thrice a week dialysis protocol, educating patients regarding their diet so that they take adequate calories and protein as permissible and preferably an AV fistula be made as soon as possible so as to avoid central venous catheterization and its associated complications. Last but not the least patients regularly follow their consulting physician / nephrologist for proper treatment, advice and guidance. This care would lead to approximately $50 \%$ lower rates of deaths during the initial four months of dialysis.

\section{REFERENCES :}

1. Collins AJ, Foley RN, Chavers B, et al: United States Renal Data System 2011 Annual Data Report: Atlas of chronic kidney disease \& end-stage renal disease in the United States. Am J Kidney Dis. 2012 Jan;59(1 Suppl 1):A7, e1-420.

2. Bradbury BD, Fissell RB, Albert JM, et al : Predictors of early mortality among incident US haemodialysis patients in the Dialysis Outcomes and Practice Patterns Study (DOPPS). Clin J Am Soc Nephrol. 2007 Jan;2(1):89-99.

3. Goldwasser P, Mittman N, Antignani A, et al : Predictors of mortality in haemodialysis patients. J Am Soc Nephrol. 1993 Mar;3(9):1613-22.

4. Avram MM, Mittman N, Bonomini L, et al : Markers for survival in dialysis: a seven-year prospective study. Am J Kidney Dis. 1995 Jul;26(1):209-19.

5. Leavey SF, Strawderman RL, Jones CA, et al : Simple nutritional indicators as independent predictors of mortality in haemodialysis patients. Am J Kidney Dis. 1998 Jun;31(6):997-1006.

6. Fernández-Reyes MJ, Alvarez-Ude F, Sánchez R, et al : Inflammation and malnutrition as predictors of mortality in patients on haemodialysis. J Nephrol. 2002 MarApr;15(2):136-43.

7. Cooper BA, Penne EL, Bartlett LH, et al : Protein malnutrition and hypoalbuminemia as predictors of vascular events and mortality in ESRD. Am J Kidney Dis. 2004 Jan;43(1):61-6.

8. Pisoni RL, Bragg-Gresham JL, Young EW, et al : Anemia management and outcomes from 12 countries in the Dialysis Outcomes and Practice Patterns Study (DOPPS). Am J Kidney Dis. 2004 Jul;44(1):94-111. 
9. Goodkin DA, Bragg-Gresham JL, Koenig KG, et al : Association of comorbid conditions and mortality in haemodialysis patients in Europe, Japan, and the United States: the Dialysis Outcomes and Practice Patterns Study(DOPPS). J Am Soc Nephrol. 2003 Dec;14(12):3270-7.

10. Block GA, Klassen PS, Lazarus JM, et al Mineral metabolism, mortality, and morbidity in maintenance haemodialysis. J Am Soc Nephrol. 2004 Aug;15(8):2208-18.

11. den Elzen WP, van Manen JG, Boeschoten EW, et al : The effect of single and repeatedly high concentrations of C-reactive protein on cardiovascular and non-cardiovascular mortality in patients starting with dialysis. Nephrol Dial Transplant. 2006 Jun;21(6):1588-95.

12. Honda H, Qureshi AR, Heimbürger 0, et al : Serum albumin, C-reactive protein, interleukin 6, and fetuin a as predictors of malnutrition, cardiovascular disease, and mortality in patients with ESRD. Am J Kidney Dis. 2006 Jan;47(1):139-48.

13. Arora P, Obrador GT, Ruthazer R, et al: Prevalence, predictors, and consequences of late nephrology referral at a tertiary care center. J Am Soc Nephrol. 1999 Jun;10(6):1281-6.

14. Kessler M, Frimat L, Panescu V, Briançon S. Impact of nephrology referral on early and midterm outcomes in ESRD: Epidemiology de l'Insuffisance REnale chronique terminale en Lorraine (EPIREL): results of a 2-year, prospective, community-based study. Am J Kidney Dis. 2003 Sep;42(3):474-85.

15. Lowrie EG, Lew NL. Death risk in haemodialysis patients: the predictive value of commonly measured variables and an evaluation of death rate differences between facilities. Am J Kidney Dis. 1990 May;15(5):458-82.

16. Weller JM, Port FK, Swartz RD, et al: Analysis of survival of end-stage renal disease patients. Kidney Int. 1982 Jan;21(1):78-83.

17. Soucie JM, McClellan WM. Early death in dialysis patients: risk factors and impact on incidence and mortality rates. J Am Soc Nephrol. 1996 Oct;7(10):2169-75.

18. Innes A, Rowe PA, Burden RP, Morgan AG: Early deaths on renal replacement therapy: The need for early nephrological referral. Nephrol Dial Transplant. 1992; 7: 467-471.

19. Khan IH, Catto GR, Edward N, MacLeod AM: Death during the first 90 days of dialysis: A case control study. Am J Kidney Dis 1995;25: 276-280.

20. Garcia-Garcia G, Deddens JA, D’Achiardi-Rey R, First MR, et al: Results of treatment in patients with end-stage renal disease: A multivariate analysis of risk factors and survival in 341 successive patients. Am J Kidney Dis 1985; 5: 10-18.

21. Wright LF: Survival in patients with end-stage renal disease. Am J Kidney Dis 1991;17: 25-28.

22. Golper TA. Redialysis nephrology care improves dialysis outcomes: now what? Or chapter two. Clin J Am Soc Nephrol. 2007 Jan;2(1):143-5.

23. Khan SS, Xue JL, Kazmi WH, Gilbertson DT, et al : Does predialysis nephrology care influence patient survival after initiation of dialysis? Kidney Int. 2005 Mar;67(3):103846.

24. Gmar-Bouraoui S, Skhiri H, Achour A, Frih A, et al : The predictors of early mortality in patients starting chronic haemodialysis. Saudi J Kidney Dis Transpl. 2003 JanMar;14(1):23-9.

25. Murphy CL, Wang S, Weaver K, Gertz MA, et al : Renal apolipoprotein A-I amyloidosis associated with a novel mutant Leu64Pro. Am J Kidney Dis. 2004 Dec;44(6):1103-9. 
26. McQuillan R, Trpeski L, Fenton S, Lok CE. Modifiable risk factors for early mortality on haemodialysis. Int J Nephrol. 2012;2012:435736.

27. National Kidney Foundation: KDOQI Clinical Practice Guidelines for Nutrition in Chronic Renal Failure. Am J Kidney Dis 2000 (suppl 1) ; 35:S1-S140.

28. Rao P, Reddy GC, Kanagasabapathy AS. Malnutrition-inflammation-atherosclerosis syndrome in Chronic Kidney disease. Indian J Clin Biochem. 2008 Jul;23(3):209-17.

29. Qureshi AR, Alvestrand A, Diviino-Filho C, Gutierez A, et al : Inflammation, malnutrition and cardiac disease as predictors of mortality in haemodialysis patients $\mathrm{J}$ Am Soc Nephrol. 2002 Jan;13 Suppl 1:S28-36.

30. Pecoits-Filho R, Bárány P, Lindholm B, Heimbürger O. Interleukin-6 is an independent predictor of mortality in patient starting dialysis treatment. Nephro Dial Transplant.2002 Sept;17(9):1684-8

31. Stehman- Breen CO, Sherrard DJ, Gillen D, Capps M. Determinants of type and timing of initial permanent haemodialysis vascular access. Kidney Int. 2000 Feb;57(2):639-45.

32. Lukowsky LR, Kheifets L, Arah OA, Nissenson AR, et al: Patterns and predictors of early mortality in incident haemodialysis patients: new insights. Am J Nephrol. 2012;35 (6):548-58. 


\section{ORIGINAL ARTICLE}

Table 1. Clinical and Biochemical parameters at starting chronic haemodialysis

\begin{tabular}{|c|c|}
\hline Clinical Parameters & $\mathrm{N}(\%)$ \\
\hline Patients & $215(100)$ \\
\hline \multicolumn{2}{|l|}{ Age } \\
\hline$<65$ years & $177(82.3)$ \\
\hline$>65$ years & $38(17.6)$ \\
\hline Males & $131(60.9)$ \\
\hline Females & $84(39.1)$ \\
\hline Chronic hypertension & $149(69.3)$ \\
\hline \multicolumn{2}{|l|}{ Primary renal disease } \\
\hline Diabetic nephropathy & $51(23.7)$ \\
\hline Tubulointerstitial & $49(22.7)$ \\
\hline Chronic glomerulonephritis & $29(13.5)$ \\
\hline Amyloidosis & $13(6)$ \\
\hline Hypertensive and renovascular & $28(13)$ \\
\hline Polycystic kidney disease & $8(3.7)$ \\
\hline Unknown & $47(21.8)$ \\
\hline Others & $8(3.7)$ \\
\hline \multicolumn{2}{|l|}{ Co morbidity } \\
\hline Septicaemia & $13(6)$ \\
\hline Shock & $3(1.4)$ \\
\hline Coma & $5(2.3)$ \\
\hline Coronary artery Disease & $35(16.2)$ \\
\hline Congestive heart failure & $25(11.6)$ \\
\hline Dysrhythmia & $14(6.5)$ \\
\hline Peripheral Vascular Disease & $15(6.9)$ \\
\hline \multicolumn{2}{|l|}{ Complicated uraemia } \\
\hline Pericarditis & $30(13.9)$ \\
\hline Pulmonary edema & $34(15.8)$ \\
\hline Gastrointestinal bleeding & $4(1.86)$ \\
\hline Urinary tract infection & $47(21.86)$ \\
\hline \multicolumn{2}{|l|}{ First haemodialysis } \\
\hline Emergency & $80(37.2)$ \\
\hline Programmed & $135(62.8)$ \\
\hline Saw Nephrologist >1 month before ESRD & $90(41.86)$ \\
\hline \multicolumn{2}{|l|}{ Vascular access type } \\
\hline Catheter & $105(48.8)$ \\
\hline AV fistula & $108(50.2)$ \\
\hline AV graft & $2(0.93)$ \\
\hline \multicolumn{2}{|l|}{ Dialysis frequency during first 120 days } \\
\hline Two times a week & $86(40.4)$ \\
\hline Three times a week & $129(59.53)$ \\
\hline \multicolumn{2}{|l|}{ Biochemical Parameters } \\
\hline S. Albumin $(<35 \mathrm{~g} / \mathrm{l})$ & $76(35.3)$ \\
\hline Haemoglobin $(<11 \mathrm{gm} / \mathrm{dl})$ & $153(71.1)$ \\
\hline S. uric acid $(>7 \mathrm{mg} / \mathrm{dl})$ & $68(31.62)$ \\
\hline S. Calcium $(<8.5$ gm/dl $)$ & $81(37.6)$ \\
\hline S. Phosphorus (>5.5 mg/dl) & $71(33)$ \\
\hline
\end{tabular}


Table 2 . Causes of Mortality

\begin{tabular}{|l|c|}
\hline Cause & $\mathrm{N}(\%)$ \\
\hline Cardiovascular causes & $20(51.2)$ \\
\hline Cardiac tamponade & 3 \\
\hline Pulmonary edema & 8 \\
\hline Severe cardiac failure & 4 \\
\hline Myocardial infarction & 3 \\
\hline Cerebrovascular accident & 2 \\
\hline Septicaemia & $8(20.5)$ \\
\hline Hyperkalemia & $6(15.3)$ \\
\hline Cardiac arrest (unknown) & $5(12.8)$ \\
\hline Total & $39(100)$ \\
\hline
\end{tabular}

Table 3. Variables associated with early mortality in the univariate analysis

\begin{tabular}{|c|c|c|c|}
\hline Variables & Deceased [n (\%)\}] & Survivors [n (\%)] & $\mathrm{P}$ \\
\hline Chronic hypertension & & & $<0.05$ \\
\hline Yes & $20(13.4)$ & $129(86.6)$ & \\
\hline No & $19(28.7)$ & $47(71.3)$ & \\
\hline \multicolumn{2}{|l|}{ Diabetes mellitus } & & $<0.05$ \\
\hline Yes & $15(29.4)$ & $36(70.6)$ & \\
\hline No & $24(14.6)$ & $140(85.4)$ & \\
\hline Urinary tract infection & & & $<0.05$ \\
\hline Yes & $14(29.8)$ & $33(70.2)$ & \\
\hline No & $25(14.9)$ & $143(85.1)$ & \\
\hline Dysrhythmia & & & $<0.05$ \\
\hline Yes & $5(35.7)$ & $9(64.3)$ & \\
\hline No & $34(16.9)$ & $167(83.1)$ & \\
\hline Vascular Access type & & & $<0.02$ \\
\hline Catheter & $28(26.7)$ & $77(73.3)$ & \\
\hline AV Fistula & $11(10.1)$ & 97 (89.9) & \\
\hline Pre ESRD > 1 month care & & & $<0.05$ \\
\hline Yes & $10(11.6)$ & $80(88.4)$ & \\
\hline No & $29(23.6)$ & $94(76.4)$ & \\
\hline Amyloidosis & & & $<0.05$ \\
\hline Yes & $5(38.4)$ & $8(66.7)$ & \\
\hline No & $34(16.8)$ & 151(83.9) & \\
\hline Treatment Frequency & & & $<0.02$ \\
\hline Two times a week & $24(27.9)$ & $62(72.1)$ & \\
\hline Three times a week & $15(11.6)$ & $114(88.4)$ & \\
\hline Serum albumin (g/1) & & & $<0.001$ \\
\hline$<35 \mathrm{~g} / \mathrm{l}$ & $26(34.2)$ & $50(65.8)$ & \\
\hline$>35 g / 1$ & $13(9.3)$ & $126(90.7)$ & \\
\hline Hemoglobin $(\mathrm{g} / \mathrm{d} 1)^{*}$ & $7 \pm 1.6$ & $8.1+2.2$ & $\mathrm{p}<0.03$ \\
\hline Triglycerides (mmol/1)* & $1.8 \pm 0.8$ & $2.3 \pm 1.3$ & $\mathrm{p}<0.03$ \\
\hline Leucocytes (x 109/1)* & $11 \pm 5.2$ & $7.8 \pm 3.4$ & $\mathrm{p}<0.002$ \\
\hline
\end{tabular}

${ }^{*}$ continuous variables are given as mean \pm SD 